\section{Summary of: Food references in UK children's magazines - an oral health perspective}

\author{
K. J. Chapman, ${ }^{1}$ R. M. Fairchild ${ }^{2}$ and M. Z. Morgan*1
}

FULL PAPER DETAILS

${ }^{1}$ Applied Clinical Research and Public Health, College of Biomedical and Life Sciences, Cardiff University, School of Dentistry, Heath Park, Cardiff, CF14 4XY; ${ }^{2}$ Cardiff Metropolitan University, Department of Healthcare and Food, Cardiff, CF5 2YB ${ }^{*}$ Correspondence to: Maria Z. Morgan Email:morganmz@cardiff.ac.uk Online article number E20 Refereed Paper - accepted 2 September 2014 DOI: 10.1038/sj.bdj.2014.1007 -British Dental Journal 2014; 217: E20

Objective Children's magazines are popular in the United Kingdom, but their content is poorly regulated. Consequently, food and beverages high in fat, salt and sugar (HFSS), detrimental to oral and wider health, make unrestricted appearances. The study aim was to assess the amount of HFSS food and drink children are exposed to while reading magazines; with particular focus on foods containing free sugars due to their known cariogenic properties, and foods with low pH due to their erosive potential. Design Eleven of the most popular UK children's magazines were selected and purchased at four separate time points in 2012. These 44 magazines were examined using content analysis; any references to food/beverages (in advertisements, free gifts, editorial and general content) were recorded. Results Of the 508 food references observed, 73.6\% (374/508) were for foods detrimental to oral health owing to their high sugar and/or acid content. 5.9\% (30/508) were considered 'unhealthy' due to their fat or salt content. 20.5\% of references were for 'healthy' foods (104/508). The most common food categories referenced were baked goods $(181 / 508)$ and sweets $(86 / 508)$. Over a third $(36.4 \%, 16 / 44)$ of magazines came with free sweets. In terms of positioning, the food/drink references were predominantly found in the general content of the magazines, including the editorial spreads. Direct advertisements for food/drink only accounted for 9.6\% (36/374) of the total number of references counted. Conclusion Food references within children's magazines are biased towards unhealthy foods especially those detrimental to oral health; these permeate throughout the general and editorial content and are not restricted to direct advertisements. Magazine editors, journalists and illustrators are responsible for the editorial and general content of magazines. Without regulation, subliminal placement of advertisements within editorial and general content leads to 'advertorials' which are known to confuse children and parents alike. This study concludes that regulation may therefore need to cover more than just the direct advertisements. Dental professionals need to be aware of current trends in children's media when giving health education advice or designing health promotion initiatives.

\section{EDITOR'S SUMMARY}

Public Health England has just released the results of a survey of 3-year-olds which shows that $12 \%$ are affected by tooth decay. Eighty-two percent of children read comics or magazines and there is no doubt that advertising is a major influence on media users. These two facts alone make this $B D J$ article significant.

One questions the extent to which adults under the influence of advertising have free will, not to mind children. Otherwise why would manufacturers spend so much money on it ( $£ 17.9$ billion in the UK alone in 2014)? In this article Maria Morgan and colleagues have determined that over two thirds of food references within children's magazines concerned products with high sugar or acid content. In addition, 97.7\% of the magazines investigated had free gifts and over a third of these were sweets. So not only is the mention of sugary or acidic foods in editorial, advertorial and advertising content an issue, this medium can actually deliver sugar to children!

This article comes at a good time in view of the current upsurge in awareness about the problems associated with sugar consumption. It has long been known by the dental profession that high levels of sugar intake are the main cause of dental caries. So now is the time to fight the sugar lobby; considering that the weight of the medical profession, media and general public is starting to move with the dental profession at last.

\section{Five things we can do right now:}

1. Advise patients to download the free UK Foodswitch App. This allows you to scan barcodes to search a database for similar but healthier alternative products if necessary: www.foodswitch. co.uk

2. Write directly to local outlets of supermarkets, cinemas etc. asking them to act responsibly when marketing food and drink, as part of the BDA's Make a meal of it campaign: www.bda.org

3. Sign the petition on the British Heart Foundation website which calls on the UK Government to close down loopholes that allow adverts for unhealthy food and drinks on TV before $9 \mathrm{pm}$ : http://extras.bhf.org.uk/junkfood/

4. Post photographs of unacceptable marketing at the checkout on the Children's Food Campaign's (childrensfood.org.uk) 'Wall of Shame'

5. Finally, talk to your patients about the findings in this paper so they know to be aware of the problem of sweet giveaways and sugary/acidic food marketing in children's magazines.

The full paper can be accessed from the $B D J$ website (www.bdj.co.uk), under 'Research' in the table of contents for Volume 217 issue 10.

Ruth Doherty Managing Editor DOI: 10.1038/sj.bdj.2014.1031 


\section{TO ACCESS THE BDJ WEBSITE TO READ THE FULL PAPER}

- BDA Members should go to www.bda.org.

- Click the 'login' button on the right-hand side and enter your BDA login details.

- Once you have logged in click the 'BDJ' tab to transfer to the BDJ website with full access.

IF YOUR LOGIN DETAILS DO NOT WORK:

- Get a password reminder: go to www.bda.org, click the login button on the right-hand side and then click the forgotten password link.

- Use a recommended browser: we recommend Microsoft Internet Explorer or Mozilla Firefox.

- Ensure that the security settings on your browser are set to recommended levels.

IF YOU HAVE NOT YET SIGNED UP TO USE THE BDA WEBSITE:

- Go to www.bda.org/getstarted for information on how to start using the BDA website.

\section{COMMENTARY}

There is currently much interest in the unacceptably high levels of free sugars being consumed, particularly by children, because of concern about rising rates of obesity and diabetes. A notable feature of the discussions about sugars and health is that the dental consequences of sugars are hardly mentioned, despite overwhelming scientific evidence that free sugars cause caries. That reflects the little emphasis given to sugars by the dental profession and a failure of dentists to collaborate with others concerned with non-communcable diseases in strategies to reduce free sugars consumption.

The WHO's Nutrition Guidance Expert Advisory Group (NUGAG) recently issued guidelines on halving current levels of free sugars consumption, as have the Scientific Advisory Committee on Nutrition (SACN) that advises Public Health England and other government agencies and departments on nutrition. Ironically, their recommendations are mainly based on the very good evidence on the dose-response relationship between sugars and caries. To achieve the recommended reductions will require concerted efforts by all health professionals. In particular, dentists, in their role as advocates, should put pressure on government, decision makers, and the media to reduce sugar levels.

One important source of misinformation that should be targeted because of its influence on sugars consumption, is children's magazines. As Chapman, Fairchild and Morgan conclude in their interesting study 'Food references within children's magazines are biased towards unhealthy foods especially those detrimental to oral health; these permeate throughout the general and editorial content and are not restricted to direct advertisements.' Seventy-four percent of references to foods in the children's magazines they reviewed were for foods detrimental to oral health owing to their high sugar and/or acid content. That should be a warning bell for dentists. A point of interest to oral health advocates is that direct advertisements for foods and drinks accounted for less than $10 \%$ of the food references. Therefore, publishers and food writers, as well as advertisers, need to be targeted and challenged about recommending and providing misleading information on foods and drinks that are harmful to health and oral health. The unabated increase in dental caries shows that such approaches are badly needed.

\section{Aubrey Sheiham \\ Emeritus Professor of Dental Public Health University College London}

\section{IN BRIEF}

- Highlights the preponderance of sugarloaded messages in pre-teens magazines.

- Discusses how sugar-loaded messages permeate throughout general and editorial content and are not restricted to direct advertisements.

- Suggests that parents and dental health professionals need to be aware of this when recommending healthier treats to children.

\section{AUTHOR QUESTIONS AND ANSWERS}

1. Why did you undertake this research? Children's magazines are popular in the United Kingdom, but their content is poorly regulated. Consequently food and beverages high in fat, salt and sugar (HFSS), detrimental to wider and oral health, make unrestricted appearances in the form of product advertisements, editorial and general content. Our goal was to assess the amount of HFSS food and drink children are exposed to whilst reading magazines; with particular focus on foods containing free sugars due to their known cariogenic properties.

\section{What would you like to do next in this} area to follow on from this work?

We would like to repeat our study to cover a wider range of magazines encompassing younger children and other socio-demographic groups. We would also like expand the research by investigating websites and other forms of non-broadcast media aimed at children. We need to disseminate our findings to health professionals working in dentistry, nutrition and public health - magazines might be viewed as an innocuous alternative treat to confectionery and colleagues need to know about the sugar-loaded messages contained within children's magazines. 